\title{
CYTOTOXIC AND GENOTOXIC EFFECTS OF CADMIUM SULFIDE NANOPARTICLES
}

\author{
O.L. Apykhtina ${ }^{1, *}$, S.M. Dybkova ${ }^{2}$, L.M. Sokurenko ${ }^{3}$, Yu.B. Chaikovsky ${ }^{3}$ \\ ${ }^{1}$ SI "Kundiiev Institute of Occupational Health of the National Academy of Medical Sciences of Ukraine", \\ Kyiv 01033, Ukraine \\ ${ }^{2}$ F.D. Ovcharenko Institute of Biocolloidal Chemistry, NAN of Ukraine, Kyiv 03142, Ukraine \\ ${ }^{3}$ O.O. Bogomolets National Medical University, Kyiv 01601, Ukraine
}

\begin{abstract}
Cadmium compounds are highly toxic substances characterized by mutagenic, genotoxic and carcinogenic effects, and having high cumulative properties. Application of cadmium nanoparticles (NPs) in medicine stimulates the study of their mechanism of action at the cellular level and at the level of organs and systems, determination of biomarkers of their action, particularly in comparison with the ionic form. The aim of the study was to compare the features of cytotoxic and genotoxic effects of cadmium sulfide (CdS) NPs of different sizes on cell cultures of different histogenesis with those of cadmium chloride $\left(\mathrm{CdCl}_{2}\right)$. Materials and Methods: In this work, we used cadmium compounds in the nanoform: NPs CdS of 4-6 nm and of 9-11 nm in size; and in the ionic form: $\mathrm{CdCl}_{2}$. The studies were conducted in vitro in cell lines - IMR-32, HEK-293 and MAEC. To count viable cells we compared the results of three basic tests: MTT (methyl tetrasolium test), SRB (sulforhodamine B test) and NRU (neutral red uptake test). We evaluated the genotoxic effect of the substances studied in vitro using DNA comet assay in alkaline conditions. Results: CdS NPs and $\mathrm{CdCl}_{2}$ demonstrated pronounced dose-dependent cytotoxic effect in MAEC, HEK-293 and IMR-32 cell lines, by impairing membrane permeability, functioning of mitochondria and lysosomes, and inhibiting the function of protein synthesis. Cytotoxic effect of $\mathrm{CdCl}_{2}$ was the most pronounced, this effect of $\mathrm{CdS}$ NPs of 9-11 nm in size being the least pronounced. The comet DNA assay in alkaline conditions revealed a statistically significant increase in DNA comet index when exposed to $\mathrm{CdCl}_{2}$ and $\mathrm{CdS}_{\mathrm{NPs}}$ in comparison with the negative control, which indicates their genotoxic effect. CdS NPs of 4-6 nm in size showed a more pronounced effect in comparison with those of 9-11 nm in size. Conclusion: Elucidation of mechanisms underlying the implementation of toxic effects of cadmium NPs will help in assessing the potential risks associated with their use in industry and developing effective preventive measures. For instance, when planning in vivo studies for toxicological evaluation of nanomaterials and nano-substances containing NPs of cadmium, it is necessary to investigate the mutagenic and carcinogenic risks and to take into account the high likelihood of neurotoxic and cardiovasotoxic effects, along with nephrotoxic effects, since high cytotoxic activity of the investigated compounds of cadmium was detected on the cells of the MAEC line (endothelial origin) and IMR-32 (neuronal origin).
\end{abstract}

Key Words: cadmium, nanoparticles, cell culture, cytotoxicity, genotoxicity.

Such heavy metals as mercury, lead, cadmium and their compounds play the leading role among the global pollutants of the environment [1-5]. In case of acute exposure excessive amounts of cadmium may get into the body, potentially causing damage to the lungs, kidneys, liver, and reproductive organs, whereas in case of chronic exposure cadmium mainly has nephrotoxic, immunotoxic and osteotoxic effects [6, 7]. In general, cadmium compounds are highly toxic substances, characterized by mutagenic and genotoxic effects and having high cumulative properties.

Cadmium and cadmium compounds have been classified as known human carcinogens by the International Agency for Research on Cancer and the National Toxicology Program based on epidemiologic studies showing a causal association with lung cancer, and possibly prostate cancer, and studies in experimental animals, demonstrating that cadmium causes cancer

Submitted: October 16, 2017.

*Correspondence: E-mail: ol_apyht@ukr.net Abbreviations used: $\mathrm{CdCl}_{2}$ - cadmium chloride; $\mathrm{CdS}$ - cadmium sulfide; DNA - deoxyribonucleic acid; LC $_{50}$ - cytotoxic concentration causing death of $50 \%$ of cells; MTT - methyl tetrasolium test; NPS - nanoparticles; NRU - neutral red uptake test; ROS - reactive oxygen species; SRB - sulforhodamine B test. development by various routes of exposure. Epidemiologic studies published since these evaluations suggest that cadmium is also associated with cancer of the breast, kidney, pancreas, and urinary bladder, and non-Hodgkin lymphoma [8-11].

Development of nanotechnology has stimulated the initiation of research of the synthesis and action of nanoparticles (NPs) of heavy metals, in particular of lead [12-14], cadmium compounds and the like and their use in various industries. Cadmium-containing nanomaterials are extensively used in optical and electronic devices, in particular in semiconductor lasers, as parts of photocells, solar cells, photo- and light emitting diodes [15]. Quantum dots based on cadmium compounds can be used as biological labels when combined with certain proteins [16].

NPs have unique physico-chemical properties, which also determine their negative impact on the body. It is known, that toxicity of metal NPs and their compounds depends on the size, surface area, particle charge, basic material, dose, route of exposure, solubility and lifetime [17-19].

The introduction of cadmium compounds NPs into production necessitated the study of their mode of action both on the cellular and the organ and systems levels, determination of biomarkers of their effects, especially in comparison with their ionic form. It should 
be emphasized that research on in vitro models on human and animal cell cultures of different organ origin, in particular, is a mandatory stage of toxicological evaluation of new NPs and nanomaterials, which allows for coordinated further experimental studies and significantly reduces the use of animals.

The results of Rodríguez-Fragoso et al. [20] showed that NPs of cadmium sulfide (CdS) stabilized by maltodextrin exhibited cytotoxic effects toward HepG2, MDA-MB-231 and CaCo-2 cell cultures, induced apoptosis, stimulated increased production of reactive oxygen species (ROS) and cell proliferation. Pujalté et al. [21] showed that CdS NPs $7.65 \pm 1.4 \mathrm{~nm}$ in size after $24 \mathrm{~h}$ incubation on the culture of kidney cells IR 15 (mesangial glomerular cells) and NL-2 (proximal tubular epithelium cells) caused morphological changes in the cells (irregular form of the nucleus, the appearance of vesicles), caused a dose-dependent cytotoxic effect, and enhanced formation of ROS. In low concentrations, they increased levels of glutathione, and decreased them in high concentrations.

The results of scientific studies revealed the following underlying mechanisms of toxic effect of cadmium NPs: the development of oxidative stress and inhibition of antioxidant system activity, genotoxic effects and impairment of calcium homeostasis in the cell, stimulation of apoptosis [21-24].

Hossain [25] showed the toxic effect of synthesized CdS NPs of $3 \mathrm{~nm}$ in size on E. coli and HeLa cells. For instance, the effects of CdS NPs changed the morphological features of bacterial cells, impaired the formation of cell walls, transcription and translation processes, and condensation and fragmentation of nuclei. HeLa cells have also undergone morphological changes, the $\mathrm{LC}_{50}$ of CdS NPs being $4 \mu \mathrm{g} / \mathrm{ml}$. A dose-dependent increase in the level of ROS in both E. coli and in HeLa cells when exposed to CdS NPs was recorded.

The novelty of the presented work lies in the fact that we studied the peculiarities of cytotoxic and genotoxic effects of CdS NPs of different sizes in comparison with the ionic form of cadmium for further toxicological evaluation of nanocompounds and nanomaterials containing cadmium compounds, and analyzed the potential occupational health risks, especially the risks of carcinogenic effects.

The aim of the study was to compare the specificities of cytotoxic and genotoxic effects of CdS NPs of various sizes with cadmium chloride $\left(\mathrm{CdCl}_{2}\right)$ on cell cultures of different organ origin.

\section{MATERIALS AND METHODS}

The following NPs of cadmium were used in the work: CdS NPs with a mean size of $4-6 \mathrm{~nm}$ and of $9-11 \mathrm{~nm}$ in the ionic form $\mathrm{CdCl}_{2}$, which is well soluble in water. CdS NPs were obtained by chemical synthesis, using sodium polyphosphate stabilizer $\left(\mathrm{NaPO}_{3}\right)_{\mathrm{n}}$. NPs dimensions were determined by electron microscopy.
Specific features of the cadmium compounds cytotoxic activity were studied in vitro on cultures of IMR-32 cells (neuronal origin), HEK-293 (kidney cells) and MAEC (endothelial cells). All cell lines were obtained from the cell bank of the R.E. Kavetsky Institute of Experimental Pathology, Oncology and Radiobiology of the National Academy of Sciences of Ukraine. The cells were cultured in a complete growth medium RPMI 1640 containing $4 \mathrm{mmol} / \mathrm{l}$ of L-glutamine (IMR-32, HEK-293) or DMEM containing $2 \mathrm{mM}$ L-glutamine (MAEC) supplemented with $10 \%$ of fetal bovine serum and $40 \mu \mathrm{g} / \mathrm{ml}$ gentamicin in a humidified atmosphere with $5 \% \mathrm{CO}_{2}$ at $37^{\circ} \mathrm{C}$. The medium was replaced every 2 days, and the cells were transferred with the trypsin solution in EDTA after they had formed a continuous monolayer.

To evaluate the cytotoxic activity of the cadmium compounds studied, the cells were plated on 96-well plates at a concentration of $1 \cdot 10^{5}$ cells per well in complete growth medium. The next day the solutions of the investigated cadmium compounds in the nano- and ion forms in concentration of $1 \cdot 10^{-3}-4.6 \cdot 10^{-7} \mathrm{~mol} / \mathrm{l}$ were added to the cells followed by incubation for $24 \mathrm{~h}$.

The cytotoxic activity of the cadmium compounds were evaluated by the indicators of cellular functional activity in the following tests: in the methyl tetrasolium test (MTT) by the activity of mitochondrial dehydrogenases; in the neutral red uptake test (NRU) by the intensity of active membrane transfer processes and lysosomal activity; in the sulforhodamine B test (SRB) [26].

The tests were conducted in three replications in two series of the experiment $(n=6)$. The $L_{50}$ cytotoxic concentration was calculated by probit analysis using SPSS 21 (SPSS Inc., USA) in each of the tests.

The genotoxic effect of the studied substances was evaluated in vitro using the comet DNA assay in alkaline conditions [27, 28]. Cells were incubated for $18 \mathrm{~h}$ in the presence of cadmium compounds at concentrations of $2 \cdot 10^{6}$ and $8 \cdot 10^{7} \mathrm{~mol} / \mathrm{l}$ (concentrations were selected based on their cytotoxic performance indicators). Cells that were incubated in the presence of $1 \mathrm{mmol}$ of $\mathrm{N}$-nitrosomethyl urea were used as a positive control, while intact cells served negative control. The tests were conducted in three replications in two series of experiment $(n=6)$.

Micro-preparations were analyzed by means of fluorescent microscopy, and "NA comets" visually. For this purpose the "DNA comets" were tentatively subdivided into five types, with each type assigned an appropriate number from 0 to 4 . The degree of DNA damage was expressed as the "DNA comet" $\left(I_{D N A}\right)$ index, calculated using the following formula:

$$
I_{D N A}=\left(0 n_{0}+1 n_{1}+2 n_{2}+3 n_{3}+4 n_{4}\right) / \Sigma \text {, }
$$

where $n_{0}-n_{4}$ is the number of "DNA comets" of each type, and $\Sigma$ is the sum of "DNA comets". Alkaline gel electrophoresis method of the isolated cells ("DNA comets"), allowed to obtain electrophoretic tracks of the "comets" type in all positive control samples. 
The primary data were statistically processed using Microsoft Excel 2003 and SPSS 21 (SPSS Inc., USA). The reliability of the differences between the scores was evaluated by Mann - Whitney U-test, with a significant difference between the scores being $p<0.05$.

\section{RESULTS AND DISCUSSION}

Study of the cytotoxic effect of $\mathrm{CdCl}_{2}$ and $\mathrm{CdS}$ NPs on MAEC cell line culture. MAEC line cells were incubated for $24 \mathrm{~h}$ with different concentrations of $\mathrm{CdCl}_{2}$ and CdS NPs after which MTT, NRU, and SRB revealed a significant dose-dependent cytotoxic activity of the cadmium compounds studied, which indicates the similar direction of these compounds effect on the membranes permeability, mitochondrial and lysosomal activity, and the protein-synthesizing function of the MAEC line cells.

The results of the probit analysis show (Table 1) that according to the results of the three tests performed to assess the functional activity of the MAEC cells, the lowest cytotoxic concentration of $\mathrm{LC}_{50}$ (causing death of $50 \%$ of cells) was recorded under the effect of $\mathrm{CdCl}_{2}$, and the highest - under the effect of CdS NPs of 4-6 nm in size. This suggests that $\mathrm{CdCl}_{2}$ in the MAEC cells culture demonstrates a greater cytotoxic effect.

Study of cytotoxic effect of $\mathrm{CdCl}_{2}$ and $\mathrm{CdS}$ NPs on cell culture of IMR-32 line demonstrated cytotoxic effects in MTT, NRU and SRB after $24 \mathrm{~h}$ incubation. When comparing the cytotoxic effect of the cadmium compounds studied on the IMR-32 cells culture by the value of $\mathrm{LC}_{50}$, it was established (see Table 1) that in the MTT and NRU tests the highest cytotoxic effect was observed in exposure to $\mathrm{CdCl}_{2}$, and in the SRB to CdS of 4-6 nm in size. This suggests that $\mathrm{CdCl}_{2}$ in cytotoxic doses is more likely to inhibit mitochondrial dehydrogenase activity, and CdS NPs the protein biosynthesis and proliferative activity.

Table 1. Cytotoxic effect of $\mathrm{CdCl}_{2}$ and CdS NPs on cell culture in three functional tests, $\mathrm{LC}_{50}$ (95\% confidence interval), $\mathrm{mmol} / \mathrm{l}$

\begin{tabular}{|c|c|c|c|}
\hline Test & $\mathrm{NP}$ of $\mathrm{CdS}_{4-6 \mathrm{~nm}}$ & $\mathrm{NP}$ of $\mathrm{CdS}_{9-11 \mathrm{~nm}}$ & $\mathrm{CdCl}_{2}$ \\
\hline \multicolumn{4}{|l|}{ MAEC cell culture } \\
\hline \multirow[t]{2}{*}{ MTT } & 0.073 & 0.051 & 0.053 \\
\hline & $(0.042-0.130)$ & $(0.029-0.090)$ & $(0.030-0.094)$ \\
\hline \multirow[t]{2}{*}{ NRU } & 0.076 & 0.076 & 0.025 \\
\hline & $(0.043-0.134)$ & $(0.043-0.137)$ & $(0.014-0.044)$ \\
\hline \multirow[t]{2}{*}{ SRB } & 0.166 & 0.104 & 0.040 \\
\hline & $(0.091-0.309)$ & $(0.057-0.190)$ & $(0.018-0.053)$ \\
\hline \multicolumn{4}{|l|}{ IMR-32 cell culture } \\
\hline \multirow[t]{2}{*}{ MTT } & 0.090 & 0.113 & 0.054 \\
\hline & $(0.040-0.206)$ & $(0.051-0.260)$ & $(0.024-0.120)$ \\
\hline \multirow[t]{2}{*}{ NRU } & 0.101 & 0.081 & 0.041 \\
\hline & $(0.044-0.238)$ & $(0.036-0.185)$ & $(0.018-0.092)$ \\
\hline \multirow[t]{2}{*}{ SRB } & 0.086 & 0.166 & 0.134 \\
\hline & $(0.036-0.204)$ & $(0.069-0.412)$ & $(0.056-0.325)$ \\
\hline \multicolumn{4}{|c|}{ HEK-293 cell culture } \\
\hline \multirow[t]{2}{*}{ MTT } & 0.286 & 1.817 & 0.031 \\
\hline & $(0.091-0.974)$ & $(0.432-9.223)$ & $(0.011-0.086)$ \\
\hline \multirow[t]{2}{*}{ NRU } & 0.267 & 1.133 & 0.034 \\
\hline & $(0.084-0.922)$ & $(0.308-4.987)$ & $(0.011-0.099)$ \\
\hline \multirow[t]{2}{*}{ SRB } & 0.440 & 0.813 & 0.013 \\
\hline & $(0.130-1.648)$ & $(0.223-3.362)$ & $(0.004-0.038)$ \\
\hline
\end{tabular}

Study of the cytotoxic effect of $\mathrm{CdCl}_{2}$ and CdS NPs on HEK-293 cell line culture. Comparative evaluation of the cytotoxic activity of the studied compounds according to the results of in MTT, NRU and $\mathrm{SRB}$ revealed that $\mathrm{CdCl}_{2}$ had the greatest cytotoxic effect on the cells of the HEK-293 line, and the effect of CdS NPs of 9-11 nm in size was the lowest. According to probit analyzes, the $\mathrm{LC}_{50}$ in these three tests was the lowest under the action of $\mathrm{CdCl}_{2}$, and the highest under the action of a CdS NPs of 9-11 nm in size.

Thus, the results of the study demonstrated pronounced dose-dependent cytotoxic effect of CdS NPS and $\mathrm{CdCl}_{2}$ on the MAEC, HEK-293 and IMR-32 cell lines cultures leading to impaired membrane permeability and functioning of mitochondria and lysosomes, and to suppressed function of protein synthesis. Cytotoxic action of $\mathrm{CdCl}_{2}$ was more pronounced (except the effect of CdS NPs 4-6 nm in size in the SRB test); the cytotoxic effect of mainly CdS (9-11 nm) was low. HEK-293 culture was the most sensitive to the cytotoxic activity of $\mathrm{CdCl}_{2}$, being less sensitive to both sizes of CdS NPs at the same time; and the MAEC cell line culture was most sensitive to the effect of CdS NPs. However, CdS NPs of both sizes in low doses that were not cytotoxic, caused an increase in cellular functional activity according to NRU and SRB tests as compared with intact cells, which may indirectly indicate stimulation of their proliferative activity.

Study of genotoxic effect of $\mathrm{CdCl}_{2}$ and $\mathrm{CdS}$ NPs on cell cultures. According to the results of the study conducted with "DNA comets" assay in alkaline conditions on the cultures of the studied cell lines a statistically significant increase of the "DNA comet" index was observed compared to the negative control, indicating the genotoxic effect of $\mathrm{CdCl}_{2}$ and $\mathrm{CdS}$ NPS (Table 2). Moreover, the of HEK-293 cell culture was the most sensitive to the genotoxic effect of the studied cadmium compounds, with the IMR-32 being the least sensitive.

Results of the MAEC line cell culture study revealed the lowest genotoxic effect of CdS NPS $(9-11 \mathrm{~nm})$ by "DNA comets" indices. The effects of CdS NPs (4-6 nm) and $\mathrm{CdCl}_{2}$ were similar, there being no statistical difference in "DNA comets" indices in these groups.

The DNA comet index in the study on IMR-32 cell line was the highest after incubation with 4-6 nm CdS NPs, being higher than that of the positive control. The DNA comet index was also high after incubation of cells with $\mathrm{CdCl}_{2}$.

The studies on the HEK-293 cell culture showed similar genotoxic effect of CdS NPs of both sizes and $\mathrm{CdCl}_{2}$ : the indices of the "DNA comets" were higher than the negative control index and there was no statistically significant difference between the former two.

"DNA comet" assay in alkaline conditions on the cultures of the studied cell lines revealed a statistically significant increase in the DNA comet index compared to the negative control, which indicate the genotoxic effect of $\mathrm{CdCl}_{2}$ and CdS NPs. CdS NPs of 4-6 nm in size demonstrated a more pronounced genotoxic effect in comparison with a 9-11 nm NP. 
Table 2. Indices of DNA comets of cells after incubation with $\mathrm{CdCl}_{2}$ and $\mathrm{CdS} \mathrm{NPs,} \mathrm{Me}\left(\mathrm{Q}_{25} ; \mathrm{Q}_{75}\right), \mathrm{mmol} / \mathrm{l}$

\begin{tabular}{|c|c|c|c|c|c|c|c|c|}
\hline \multirow{2}{*}{ Cell culture } & \multicolumn{2}{|c|}{$\mathrm{NP}$ of $\mathrm{CdS}_{4-6 \mathrm{~nm}}$} & \multicolumn{2}{|c|}{$\mathrm{NP}$ of $\mathrm{CdS} \mathrm{S}_{9-11 \mathrm{~nm}}$} & \multicolumn{2}{|c|}{$\mathrm{CdCl}_{2}$} & \multicolumn{2}{|c|}{ Control } \\
\hline & $2 \cdot 10^{-6} \mathrm{~mol} / \mathrm{l}$ & $8 \cdot 10^{-7} \mathrm{~mol} / \mathrm{l}$ & $2 \cdot 10^{-6} \mathrm{~mol} / \mathrm{l}$ & $8 \cdot 10^{-7} \mathrm{~mol} / \mathrm{l}$ & $2 \cdot 10^{-6} \mathrm{~mol} / \mathrm{l}$ & $8 \cdot 10^{-7} \mathrm{~mol} / \mathrm{l}$ & Positive & Negative \\
\hline MAEC & $1.95^{\star}$ & $1.90^{\star}$ & $0.85^{\star} \#^{\wedge}$ & $0.90^{\star \# \wedge}$ & $2.00^{\star}$ & $1.95^{\star}$ & $2.40^{\star}$ & 0.15 \\
\hline & $(1.88 ; 2.13)$ & $(1.88 ; 2.05)$ & $(0.78 ; 1.13)$ & (0.88; & $(1.88 ; 2.13)$ & $(1.95 ; 2.10)$ & $2.30 ; 2.58)$ & $(0.10 ; 0.23)$ \\
\hline HEK-293 & $1.00^{*}$ & $1.00^{*}$ & $1.00^{*}$ & $0.95^{\star}$ & $1.05^{\star}$ & $1.00^{*}$ & $1.15^{\star}$ & 0.15 \\
\hline & $(0.88 ; 1.20)$ & $(0.90 ; 1.13)$ & $(0.88 ; 1.13)$ & $(0.88 ; 1.10)$ & $(0.90 ; 1.20)$ & $(0.88 ; 1.20)$ & $(1.05 ; 1.20)$ & $(0.10 ; 0.23)$ \\
\hline IMR-32 & $\begin{array}{c}2.10^{\star \wedge} \\
(1.98 ; 2.25)\end{array}$ & $\begin{array}{c}1.85^{\star} \\
(1.78 ; 1.93)\end{array}$ & $\begin{array}{c}0.70^{\star \# \wedge} \\
(0.70 ; 0.83)\end{array}$ & $\begin{array}{c}0.90^{\star \# \wedge} \\
(0.88 ; 1.03)\end{array}$ & $\begin{array}{c}1.90^{*} \\
(1.90 ; 2.03)\end{array}$ & $\begin{array}{c}1.95^{\star} \\
(1.88 ; 2.03)\end{array}$ & $\begin{array}{c}1.75^{\star} \\
(1.68 ; 1.83)\end{array}$ & $\begin{array}{c}0.25 \\
(0.18 ; 0.30)\end{array}$ \\
\hline
\end{tabular}

Note: *Statistically significant as compared to intact cells (with negative control); " ${ }^{\wedge}$ statistically significant as compared to CdS NPs and $\mathrm{CdCl}_{2}$; by Mann - Whitney U-test, with statistically significant difference between indices $p<0.05$.

Cytotoxic activity of cadmium compounds NPs is largely due to the specific features of cadmium action. Mechanisms for the development of cadmium intoxication have been studied by researchers for several decades. On different cell types it was shown that cadmium ions enter the cell through the calcium channels of the plasma membrane and bind to the cytoplasmic and nuclear material. In high concentration cadmium inhibits biosynthesis of DNA, RNA and protein, causing DNA breaks and chromosomal aberrations [29]. Jie et al. [6] have shown that oxidative stress plays an important role in the implementation of cytotoxic and genotoxic effect of cadmium and the development of apoptosis. In the studies on $\mathrm{HepG} 2$ cell culture $\mathrm{CdCl}_{2}$ caused a dose-dependent decrease in cell viability, stimulated lipid peroxidation due to the increased formation of ROS, induced DNA damage and caused apoptosis in cells [30].

Cadmium causes impairment of thiol homeostasis in a cell characterized by a decrease in glutathione levels and also by direct interaction with sulfhydryl groups of proteins due to their high affinity with them, which leads to their structural deformation and changes in the catalytic activity of enzymes [31], and also competes with $\mathrm{Zn}$ (II) in proteins and binds to the DNA bases causing single-stranded DNA breaks [32].

It has been reported that cadmium also modulates the expression of genes and signaling in a cell [33], increases the ROS production and inhibits the activity of antioxidant enzymes [34], prevents DNA repair [35]. Thus, our earlier studies have shown that cadmium impaired the expression of SNF1/AMP-activated protein kinase (SNARK) genes in experimental rats after subchronic exposure, which may lead to a disruption of signaling cascades in cells [36-38].

Results of in vitro experiments have shown cadmium to induce DNA damage in bacteria [39], cause single-stranded DNA breaks and disrupt the synthesis of nucleic acids and proteins [40]. In low concentrations cadmium stimulates DNA synthesis and cell proliferation, it also increases the expression of early genes (c-fos, c-jun, and c-myc), the p53 tumor suppressor gene, as well as genes encoding the synthesis of protective molecules, including metallothioneins, glutathione, and stress proteins (thermal shock), indicating modification of cellular signaling processes, phosphorylation of proteins, and transcription factors [41].

Researchers distinguish two important ways of mutagenesis under effect of cadmium: increased ROS production and stimulation of oxidative DNA damage, as well as inhibition of DNA repair, which reduces genetic stability of the cell and increases the likelihood of mutations [42].

Thus, the following processes underlie the impairment of homeostatic mechanisms in the cell under the effect of cadmium: increased production of ROS and inhibition of the antioxidant system, the development of oxidative stress and stimulation of lipid peroxidation, impairment of calcium homeostasis and signaling processes, direct interaction of cadmium with sulfhydryl groups of proteins, leading to changes in the activity of enzymes, which plays an important role in the implementation of cytotoxic and genotoxic effects.

Taking into account the specifics of the NPs effect on the cell, one can assume that cadmium compounds in nanoform, especially of small sizes up to $5 \mathrm{~nm}$, will exhibit more pronounced cytotoxic and genotoxic effects compared to the ionic form.

The above-mentioned mechanisms for the implementation of cytotoxic action of cadmium underlie carcinogenic induction. As discussed previously, cadmium causes cancers in experimental animals at multiple tissue sites. Huff et al. [8] believe that the mechanism of carcinogenicity is multi-factorial. Like other toxic metals cadmium may act with the help of molecular/atomic mimicry of essential nutrient metals, zink and selenium in particular, which take an active part in proliferation processes. It has a wide spectrum of cellular and molecular effects, including both genetic and epigenetic ones, which could affect all stages in the carcinogenic process.

Cadmium-induced biochemical changes may play roles in all stages of carcinogenicity (initiation, promotion, and progression). For example: 1) induction of oxidative stress in combination with decreased DNA repair can lead to DNA damage, and gene mutation, resulting in preneoplastic lesions; 2) aberrant gene expression and signaling in combination with inhibition of DNA methylation induce proto-oncogenes which results in cell proliferation; and 3) E-cadherin dysfunction disrupts cell adhesion and causes tumor progression. Moreover, cadmium compounds are comutagens in mammalian cells when combined with genotoxic agents [43].

Summarizing the results of the above, we can draw the following conclusions. Cadmium compounds, both in ionic form $\left(\mathrm{CdCl}_{2}\right)$ and in nanoform (CdS NPs) exhibit pronounced dose-dependent cytotoxic and genotoxic effects. $\mathrm{CdCl}_{2}$ showed more pronounced cytotoxic activity, compared to the CdS NPs (of MAEC, HEK-293); at the same time, CdS NPs of $9-11 \mathrm{~nm}$ in size had 
a lower toxic effect, in comparison with 4-6 nm CdS NPs. Cadmium compounds caused an increase in the index of DNA comets. CdS NPs of 9-11 nm in size exhibited a lower genotoxic effect, compared with NPs of $4-6 \mathrm{~nm}$ and $\mathrm{CdCl}_{2}$.

The identification of mechanisms for the implementation of toxic effects of cadmium compounds NPs will allow to assess the potential risks associated with their use in industry and to develop effective preventive measures. In particular, when planning in vivo studies in toxicological evaluation of nanomaterials and NPs containing cadmium NPs, it is necessary to study the mutagenic and carcinogenic risks, and also to take into account the high likelihood of development of neurotoxic and cardiovasotoxic effects, along with nephrotoxic effects, as the high cytotoxic activity of the investigated cadmium compounds was detected on the cells of the MAEC cell line of endothelial origin and IMR-32 cells of neuronal origin.

\section{REFERENCES}

1. Kim HS, Kim YJ, Seo YR. An overview of carcinogenic heavy metal: molecular toxicity mechanism and prevention. J Cancer Prev 2015; 20: 232-40.

2. Kaminsky RF, Sokurenko LM, Chaikovsky YuB. Status of rats myocardium under subchronic mercury exposure and its pharmacological correction. Curr Issues Pharm Med Sci 2016; 29: 167-70.

3. Sokurenko LM, Savchyna M, Litus VI, et al. Rat spinal ganglia in assessment of protective action of antioxidants: A morphological study. Medicina (Kaunas) 2017; 53: $217-23$.

4. Sokurenko LM, Chaikovskii YuB. Mildronate protects neuroblasts against toxic influence of mercuric chloride in cell culture. Neurophysiology 2014; 46: 271-3.

5. Sokurenko LM, Chaikovskii YuB. Protective effects of Thiotriazolinum and Mildronate against mercury chloride toxicity in neuroblastoma cell culture. Neurophysiology 2016; 48: $171-5$.

6. Jie L, Wei Q, Kadiiska MB. Role of oxidative stress in cadmium toxicity and carcinogenesis. Toxicol Appl Pharmacol 2009; 238: 209-14.

7. Jarup L, Berglund M, Elinder C, et al. Health effects of cadmium exposure - a review of the literature and a risk estimate. Scand J Work Env Health 1998; 1: 1-52.

8. Huff J, Lunn RM, Waalkes MP, et al. Cadmiuminduced cancers in animals and in humans. Int $\mathbf{J}$ Occup Environ Health 2007; 13: 202-12.

9. Cadmium. International Agency for Research on Cancer (IARC), Lyon, France, 1993.

10. Joseph P. Mechanisms of cadmium carcinogenesis. Toxicol Appl Pharmacol 2009; 238: 272-9.

11. Adams SV, Passarelli MN, Newcomb PA. Cadmium exposure and cancer mortality in the Third National Health and Nutrition Examination Survey cohort. Occup Environ Med 2012; 69: 153-6.

12. Omel'chuk ST, Aleksiichuk VD, Sokurenko LM. Biochemical parameters of blood and morpho-functional state of the liver of experimental animals by the actions of lead sulfide nanoparticles in different time study. Lik Sprava 2014; (3-4): 114-8 (in Ukrainian).

13. Omelchuk ST, Aleksijchuk VD, Sokurenko LM, et al. Characteristics of rat liver exposed to nanoparticles of lead compounds. Georgian Med News 2016; 261: 94-9.
14. Aleksiichuk V, Omelchuk S, Sokurenko L, et al. The influence of lead nanoparticles on the dynamics of morphofunctional changes of rat liver during the postexposure period. Microsc Res Tech 2018; 13. doi: 10.1002/jemt.23036.

15. Liu L, Sun M, Li Q, et al. Genotoxicity and cytotoxicity of cadmium sulfide nanomaterials to mice: comparison between nanorods and nanodots. J Envir Eng Sci 2014; 31: 373-80.

16. Kozhevnikova NS, Vorokh AS, Uritskaya AA. Cadmium sulfide nanoparticles prepared by chemical bath deposition. Russ Chem Rev 2015; 84: 225-50.

17. Trakhtenberg IM, Dmytrukha NM, Apykhtina OL. Nanotoxicology/preventive toxicology and medical ecology. In: Trakhtenberg IM, ed. Selected Lectures for Scientists, Doctors and Students. Kyiv, 2011; 11: 118-23 (in Ukrainian).

18. Yavorovsky OP, Tkachyshyn VS, Arustamian OM, et al. Nanomaterials and nanoparticules: structure, physic-chemical and toxicological properties, impact on the organism of the workers. Environ Heath 2016; 3: 29-36 (in Ukrainian).

19. Rzigalinski BA, Strobl JS. Cadmium-containing nanoparticles: perspectives on pharmacology and toxicology of quantum dots. Tox Appl Pharm 2009; 238: 280-8.

20. Rodríguez-Fragoso P, Reyes-Esparza J, LeónBuitimea A, et al. Synthesis, characterization and toxicological evaluation of maltodextrin capped cadmium sulfide nanoparticles in human cell lines and chicken embryos. J Nanobiotechnology 2012; 10: 47.

21. Pujalté I, Passagne I, Brouillaud B, et al. Cytotoxicity and oxidative stress induced by different metallic nanoparticles on human kidney cells. Part Fibre Toxicol 2011; 8: 10.

22. Nguyen KC, Willmore WG, Tayabali AF. Cadmium telluride quantum dots cause oxidative stress leading to extrinsic and intrinsic apoptosis in hepatocellular carcinoma HepG2 cells. Toxicology 2013; 306: 114-23.

23. Nguyen KC, Rippstein P, Tayabali AF, Willmore WG. Mitochondrial toxicity of cadmium telluride quantum dot nanoparticles in mammalian hepatocytes. Toxicol Sci 2015; 146: 31-42.

24. Rodríguez-Fragoso P, Reyes-Esparza J, LeónBuitimea A, Rodríguez-Fragoso L. Synthesis, characterization and toxicological evaluation of maltodextrin capped cadmium sulfide nanoparticles in human cell lines and chicken embryos. J Nanobiotechnology 2012; 10: 47.

25. Hossain ST. Toxicity of cadmium sulphide (CdS) nanoparticles against Escherichia coli and HeLa cells. J Hazard Mater 2013; 260: 1073-82.

26. Trakhtenberg IM, Marchenko ML, Bezneevichnyh NO, Kudryavets YY. Advantages of the method of studying the toxic effects of heavy metal compounds in human cell culture in vitro compared with the traditional in vivo method on the animal as more reliable and adequate. Modern Problems Toxicology 2010; (2-3): 69-72 (in Ukrainian).

27. Dibkova SM. The method of DNA comets in the assessment of the safety of nanoparticles of metals for biotechnological and medical purposes. Bull Biol Med 2014; 112: 279-83 (in Ukrainian).

28. Didenko VV. Methods in Molecular Biology. In Situ Detection of DNA Damage. Methods and protocols. Totowa: Humana Press, 2002. 299 p.

29. Jin YH, Clark AB, Slebos RJ, et al. Cadmium is a mutagen that acts by inhibiting mismatch repair. Nat Genet 2003; 34: 326-9.

30. Skipper A, Sims JN, Yedjou CG, Tchounwou PB. Cadmium chloride induces DNA damage and apoptosis of human liver carcinoma cells via oxidative stress. Int J Environ Res Public Health 2016; 13: 88. 
31. Valko M, Morris H, Cronin MTD. Metals, toxicity and oxidative stress. Curr Med Chem 2005; 12: 1161-208.

32. McMurray CT, Tainer JA. Cancer, cadmium and genome integrity. Nat Genet 2003; 34: 239-41.

33. Thévenod F, Lee W-K. Cadmium and cellular signaling cascades: interactions between cell death and survival pathways. Arch Toxicol 2013: 87: 1743-86.

34. Oh SH, Lim SC. A rapid and transient ROS generation by cadmium triggers apoptosis via caspase-dependent pathway in HepG2 cells and this is inhibited through $\mathrm{N}$-acetylcysteinemediated catalase upregulation. Toxicol Appl Pharmacol 2006; 212: 212-23.

35. Pathak N, Khandelwal S. Oxidative stress and apoptotic changes in murine splenocytes exposed to cadmium. Toxicology 2006: 220: 26-36.

36. Bertin G, Averbeck D. Cadmium: cellular effects, modifications of biomolecules, modulation of DNA repair and genotoxic consequences (a review). Biochimie 2006; 88: 1549-9.

37. Bozhko I, Minchenko D, Mykhalchenko V, et al. Effect of manganese, cadmium, plumbum and mercury ions on the expression of SNF1/AMP-activated protein kinase in the rat liver, lungs, kidney and heart. An Univ Mariae CurieSklodowska 2010; 23: 193-8.

38. Jin YH, Clark AB, Slebos RJ, et al. Cadmium is a mutagen that acts by inhibiting mismatch repair. Nat Genet 2003; 34: 326-9.

39. Tsuzuki K, Sugiyama M, Haramaki N. DNA singlestrand breaks and cytotoxicity induced by chromate (VI), cadmium (II), and mercury (II) in hydrogen peroxide-resistant cell lines. Environ Health Perspect 1994; 102: 341-2.

40. Mitra RS. Protein synthesis in Escherichia coli during recovery from exposure to low levels of $\mathrm{Cd}^{2+}$. Appl Environ Microbiol 1984; 47: 1012-6.

41. Beyersmann D, Hechtenberg S. Cadmium, gene regulation, and cellular signalling in mammalian cells. Toxicol Appl Pharmacol 1997; 144: 247-61.

42. Filipic M, Fatur T, Vudrag M. Molecular mechanisms of cadmium induced mutagenicity. Hum Exp Toxicol 2006; 252: 67-77.

43. Waisberg M, Joseph P, Hale B, Beyersmann D. Molecular and cellular mechanisms of cadmium carcinogenesis. Toxicology 2003; 192: 95-117. 